\title{
EL DERECHO A LA INTIMIDAD DE LOS TRABAJADORES Y ACCESO DEL PATRÓN A LOS CORREOS ELECTRÓNICOS EMPRESARIALES Y PRIVADOS
}

\author{
O DIREITO À PRIVACIDADE DOS TRABALHADORES E EMPREGADORES E ACESSO A E-MAILS DE \\ TRABALHO E PRIVADOS
}

Amalia Patricia Cobos Campos ${ }^{1}$

\begin{abstract}
Resumen: El uso imparable de tecnologías y su inadecuada regulación legal, constituyen sin duda un problema pendiente de resolver por el derecho, la constante colisión de derechos y la vulneración de los mismos de tan cotidiano se vuelve preocupante. En este contexto entre los derechos humanos más vulnerables se encuentran indudablemente los derechos a la privacidad e intimidad, que las nuevas tecnologías parecen avasallar, y cuya tutela resulta aún muy deficientes en los ordenamientos jurídicos, tal vulnerabilidad se ve agravada cuando se enfrentan intereses privados con los derechos en mención, esos intereses en el ámbito laboral están representados por la figura del patrón, y sus facultades de supervisión con frecuencia violentan la intimidad y privacidad de sus trabajadores. Por ello cuando el patrón proporciona equipos de cómputo para uso en el trabajo e incluso correos empresariales, resulta necesario marcar los límites de las aludidas facultades de supervisión. El presente trabajo, de corte teórico-dogmático, busca analizar el status quo en la materia, partiendo de clarificar conceptualmente a ambos derechos y de ahí pasamos a analizar la construcción jurídica y jurisprudencial de tales derechos en México, para concluir con una propuesta concreta y viable de reforma legislativa que abonaría a resolver el conflicto de derechos materia de nuestro estudio; sustentándose además aportes doctrinarios.
\end{abstract}

Palabras clave: Intimidad. Privacidad. Trabajadores. Acceso a correos electrónicos.
Resumo: O uso imparável de tecnologias e sua regulação jurídica inadequada, sem dúvida um problema pendente de resolução sobre o direito, a colisão constante de direitos e violações deles como diariamente se torna preocupante. Neste contexto, os direitos humanos mais vulneráveis são, sem dúvida, o direito à privacidade e à intimidade que as novas tecnologias parecem superar e cuja protecção ainda é muito deficiente nos sistemas jurídicos, tal vulnerabilidade é agravada quando os interesses privados são confrontados com os direitos em Questão, esses interesses no local de trabalho são representados pelo empregador, e seus poderes de supervisão freqüentemente violam a privacidade ea intimidade de seus trabalhadores. Por conseguinte, quando o empregador fornece equipamento informático para utilização no trabalho e até mesmo e-mails comerciais, é necessário marcar os limites dos poderes de supervisão acima mencionados. $O$ presente trabalho, teórico-dogmático, procura analisar o status quo na matéria, partindo de um esclarecimento conceitual de ambos os direitos e daí procedeu a analisar a construção jurídica e jurisprudencial de tais direitos no México, concluir com uma proposta concreta e viável Reforma legislativa que pagaria para resolver o conflito de direito assunto do nosso estudo; apoiado por contribuições doutrinárias.

Palavras-chave: Direito à privacidade. Trabalhadores. Acesso a e-mails.

\footnotetext{
1 Doctora en Derecho por la Universidad Autónoma de Chihuahua; Profesora investigadora de tiempo completo en la Universidad Autonoma de Chihuahua; Coordinadora del Centro de Investigaciones Jurídicas; Avenida C. Escorza, 900, Centro, 31000, Chihuahua, Chih. México; pcobos@uach.mx
} 


\section{Introducción}

En la eterna lucha de los derechos fundamentales, por su consagración, protección y equilibrio entre las fuerzas de la sociedad, encontramos siempre inmiscuidos a los avances tecnológicos, que generan nuevos retos para el derecho, en su permanente búsqueda de soluciones que permitan la sana convivencia de los ciudadanos.

Hablar de la intimidad no es hablar de un tema de gran novedad, es una temática que ha inquietado al estado desde sus orígenes, żcuáles son los límites entre lo público y lo privado?, żquién los determina?

Es evidente que la respuesta a estas preguntas ha variado conforme evoluciona el Estado, además de que, se ve altamente definida por el sistema y bases ideológicas del mismo, cuando es totalitario, por ejemplo, encontraremos grandes diferencias con lo que estima íntimo respecto de uno de corte democrático; sin embargo, en general, es de reconocerse, que, en cualquiera de ellos, existen ámbitos que antes carecían de interés e importancia para éste y que hoy la tienen en forma indubitable.

El solo hecho de conceptualizar el derecho a la intimidad, representa para los juristas modernos un gran reto, $y$, partiendo de esa dificultad, se han desarrollado importantes estudios e investigaciones que han llevado a muchos países a legislar al respecto. La idoneidad de esas regulaciones legales y la ausencia de la misma en muchos otros países, siguen siendo cuestión de debate entre los juristas.

Entre los puntos de discusión más álgidos al respecto, se encuentran los que se refieren al derecho a la intimidad de los trabajadores frente al derecho del patrón a la vigilancia; el uso de videocámaras en lugares públicos, el relativo a los pacientes con enfermedades contagiosas, el que debiera darse en los centros penitenciarios, y qué decir de las vejaciones a la intimidad que sufren las personas de la tercera edad en aras del supuesto o real cuidado que se les da; de igual manera, en los últimos tiempos, surgen los cuestionamientos en cuanto a las investigaciones del mapa genético de los ciudadanos, etc.; todos ellos al no estar debidamente regulados, constituyen verdaderos asideros para la vulneración, no únicamente del derecho a la intimidad, sino incluso de los demás derechos fundamentales.

Estrechamente unido al concepto de dignidad humana, el derecho a la intimidad representa el reducto necesario en el que ésta deberá resguardarse, porque de no ser así, el Estado habrá fracasado en la importante misión que le ha sido conferida, en tanto celoso guardián de los más altos valores de la persona.

En este trabajo abordaremos los aspectos laborales de este derecho desde la perspectiva de las facultades de supervisión del patrón.

Es incuestionable que las empresas ante el imparable avance tecnológico requieren de herramientas informáticas para su quehacer cotidiano, a la vista de ello, se ha implementado el uso de correo electrónicos como una herramienta de trabajo que millones de trabajadores utilizan; como consecuencia de ello resulta necesaria plantearse el límite de las facultades de supervisión del patrón, respecto al 
contenido de los correos que el trabajador envía y la manera como esta supervisión puede incidir en dos derechos humanos de primordiales como lo son el derecho a la privacidad y el derecho a la intimidad.

El presente trabajo, de corte teórico dogmático, analiza la problemática planteada y establece el marco conceptual que rodea los derechos en conflicto, realizando un análisis doctrinario, legislativo y jurisprudencial que le permite sustentar las conclusiones planteadas, utilizando para ello, esencialmente, la hermenéutica jurídica.

\section{Un asomo a los derechos a la privacidad e intimidad}

Cualquier estudio que se realice en la temática del Derecho a la intimidad deberá, como punto de partida, realizar el somero análisis de lo que son los derechos fundamentales, para no perdernos en vericuetos conceptuales, partiremos en principio e la concepción no jurídica que os proporciona la $\mathrm{ONU}$, que los concibe de la siguiente forma: "los derechos humanos son las condiciones de la existencia humana que permiten al ser humano desenvolverse y utilizar plenamente sus dotes de inteligencia y de conciencia en orden a la satisfacción de las exigencias fundamentales que le imponen su vida espiritual y natural" (Solar Rojas, 2000, p. 21).

Esta concepción podemos complementarla con la reflexión que del tema hacen Ferrajoli (2001, p. 22) y Nikken (1994, p. 15), para el primero de ellos, los "Derechos Humanos son los derechos primarios de las personas y conciernen indistintamente a todos los seres humanos"; y para el segundo mencionado, "[1] a sociedad contemporánea reconoce que todo ser humano, por el hecho de serlo, tiene derechos frente al Estado, derechos que éste, o bien tiene el deber de respetar y garantizar o bien está llamado a organizar su acción a fin de satisfacer su plena realización."

Y por último citamos a Pérez Luño (1995, p. 46), para quién los derechos humanos son el "conjunto de facultades e instituciones que, en cada momento histórico, concretan las exigencias de la dignidad, la libertad y la igualdad humanas, las cuales deben ser reconocidas positivamente por los ordenamientos jurídicos a nivel nacional e internacional."

Con estas concepciones podemos clarificar que el derecho en análisis goza de la característica de ser un derecho humano, que en sí mismo parafraseando al último citado concreta en particular la dignidad y libertad humanas. Así lo refuerza Pacheco Escobedo (2011, pp. 83-96), quien opina que el derecho a la intimidad es un derecho humano y que "es un bien tan cercano a la persona misma que no hay duda sobre la necesidad de su respeto por parte de todos los demás y por tanto del derecho que tiene todo hombre a que no intervengan extraños en esa esfera.

"Es un derecho unido naturalmente a la persona, y ésta tiene derecho a su identidad, a conservar sólo para sí o para sus íntimos aquellos aspectos de su vida en los cuales no tienen por qué intervenir extraños" (Pacheco Escobedo, 2011, pp. 87-88).

Pasemos en consecuencia, a analizar el proceso que dio vida al derecho a la intimidad para después poder analizarla como derecho, Los antecedentes del derecho a la intimidad los podemos 
hacer derivar sin mucho esfuerzo de las corrientes del individualismo, coincidimos con Calle Sol (2009, pp. 120-121) en que son pensadores de la talla de Locke y Stuart Mill, quienes inician un proceso de reconocimiento de nuevos enfoques a la libertad, en cuanto a derecho de disposición, dejando al Estado fuera de determinadas cuestiones personales, ya que como acertadamente afirma Bru Cuadrada (2007).

[E]1 reconocimiento del derecho a la intimidad sirvió a la sociedad burguesa para protegerse frente al intervencionismo y arbitrariedad de los poderes públicos. La intimidad suponía una faceta de autonomía, aislamiento y exclusión frente a las intervenciones públicas en la vida privada. La concepción liberal equiparó la intimidad a un objeto más entre las posesiones privadas del individuo. Posteriormente, nuevas necesidades de protección fueron surgiendo y la concepción patrimonial del derecho sufrió cambios importantes.

Ya lo visualizaba con claridad Constant citado por Holmes y Shand (1995), al afirmar que "la verdadera libertad es una mezcla óptima de lo público y lo privado, de la participación y la no participación, de la responsabilidad cívica y de la independencia, del activismo y del apoliticismo." (pp. 120-123).

Sin embargo, existe un consenso generalizado en el sentido de estimar que el precedente esencial del derecho a la intimidad lo constituye el famoso artículo de Warren \& Brandies, publicado en 1890 en la Harvard Law Review intitulado The Right of Privacy, analizan en su artículo que la factibilidad de que el gobierno y otros organismos públicos y privados estén en posibilidad de invadir aspectos antes inaccesibles de la vida personal de los ciudadanos, hacen necesario que el derecho evolucione a la par de los cambios tecnológicos, aludía al propósito de determinar si la ley ofrecía una protección a la vida privada de los ciudadanos y de ser así, cuál, se preguntaba, sería su alcance.

A pesar de los argumentos vertidos en el artículo por Samuel D. Warren y Louis D. Brandeis, no fue hasta 1965 que la Corte Suprema de los Estados Unidos, reconoció de manera específica al derecho a la privacidad, en el caso "Griswod vs Connecticut State", el tribunal en su resolución decretó la inconstitucionalidad de la norma que prohibía la venta y utilización de anticonceptivos por considerarla lesiva al derecho a la privacidad.

El concepto de privacidad ha ido evolucionando, ya que aspectos de la vida de los individuos que fueron ajenos al Estado han dejado de serlo, esto es la vida privada prescinde de ser sólo una cuestión doméstica, para convertirse en una tarea del Estado, como ha reconocido el Tribunal Europeo de Derechos Humanos (TEDH, 2004).

Pero como todas las declaraciones de derechos, la verdadera importancia de las mismas estriba en la posibilidad de que los titulares puedan hacer efectivos sus derechos, puedan ejercerlos y exigir su reconocimiento, dice Calle Sol (2009, p. 121), y añade, tratándose del derecho a la intimidad, el desenvolvimiento de las sociedades ha conllevado una transformación en éste derecho de la persona, pasando del determinismo individual a la autodeterminación informativa, como consecuencia del fenómeno tele-informático que va invadiendo todas las esferas de la vida moderna. 
En efecto, la tecnología y su aplicación a sistemas de comunicación cada vez más avanzados, pone en evidencia la necesidad de controlar y regular el movimiento creciente de bases de datos de contenido personal, en algunas áreas sensibles de la sociedad, como lo son: la salud, el sistema financiero, la educación, lo judicial y por supuesto en el ámbito laboral que analizaremos en el presente trabajo.

La respuesta que gran parte de los Estados ha dado a esa necesidad de regulación se encuentra en las normas denominadas de protección de datos de carácter personal y, es de reconocerse que bajo este esquema, el derecho a la intimidad cobra una relevancia sin precedentes cuyo principal mecanismo de tutela lo constituye el habeas data.

La construcción y límites de los derechos a la privacidad e intimidad, a la luz de la legislación mexicana presentan muchos claroscuros, nuestra carta fundamental no contiene una consagración explícita de los mismos como derechos humanos y hace referencia a ellos de manera accesoria, relacionándolos con otros derechos: resultando procedente aclarar que el derecho moderno ha establecido una separación entre los derechos a la privacidad e intimidad, a la que en párrafos subsecuentes aludiremos.

Así, encontramos que en principio el derecho a la intimidad no se menciona en el contenido de nuestra carta magna en ningún precepto, y por lo que hace a la privacidad, resulta de interés para nuestro análisis el artículo $6^{\circ}$ (México, 1917), cuyo primer párrafo es del siguiente tenor literal.

Artículo 6o. La manifestación de las ideas no será objeto de ninguna inquisición judicial o administrativa, sino en el caso de que ataque a la moral, la vida privada o los derechos de terceros, provoque algún delito, o perturbe el orden público; el derecho de réplica será ejercido en los términos dispuestos por la ley. El derecho a la información será garantizado por el Estado. . .

Como es sencillo apreciar, el numeral no pretende tutelar el derecho a la privacidad en sí mismo considerado, sino únicamente establecer límites a otro derecho fundamental como lo es la libre expresión de las ideas, en donde si se realiza mención expresa al derecho a la vida privada es en el inciso A, fracción II del propio artículo (México, 1917), que determina:

Artículo 6o....

A. Para el ejercicio del derecho de acceso a la información, la Federación, los Estados y el Distrito Federal, en el ámbito de sus respectivas competencias, se regirán por los siguientes principios y bases:

II. La información que se refiere a la vida privada y los datos personales será protegida en los términos y con las excepciones que fijen las leyes.

..

Como vemos pese a que alude como ya se dijo expresamente a la vida privada, continua haciéndolo en un afán restrictivo del diverso derecho que consagra el numeral, por lo que, la tutela que pudiera conferirse al derecho a la privacidad, partiendo de su sola mención restrictiva, es parva y sin construcción jurídica propiamente dicha, cuando menos en el canon constitucional en análisis, remitiendo claramente a la ley secundaria para su determinación. 
De este precepto debemos trasladarnos hasta el artículo 16 constitucional (México, 1917), que en su décimo segundo y décimo tercer párrafo determina:

Artículo 16....

Las comunicaciones privadas son inviolables. La ley sancionará penalmente cualquier acto que atente contra la libertad y privacía de las mismas, excepto cuando sean aportadas de forma voluntaria por alguno de los particulares que participen en ellas. El juez valorará el alcance de éstas, siempre y cuando contengan información relacionada con la comisión de un delito. En ningún caso se admitirán comunicaciones que violen el deber de confidencialidad que establezca la ley.

Exclusivamente la autoridad judicial federal, a petición de la autoridad federal que faculte la ley o del titular del Ministerio Público de la entidad federativa correspondiente, podrá autorizar la intervención de cualquier comunicación privada. Para ello, la autoridad competente deberá fundar y motivar las causas legales de la solicitud, expresando además, el tipo de intervención, los sujetos de la misma y su duración. La autoridad judicial federal no podrá otorgar estas autorizaciones cuando se trate de materias de carácter electoral, fiscal, mercantil, civil, laboral o administrativo, ni en el caso de las comunicaciones del detenido con su defensor.

De nueva cuenta el texto constitucional evidencia una ausencia de construcción de los derechos en estudio, toda vez que nos habla de mecanismos de tutela de ambos derechos al proteger las comunicaciones privadas, estos párrafos son de particular interés para nuestro tema, ya que deberemos dilucidar si los correos electrónicos que el trabajador envía serán comunicaciones privadas o no.

Previo a ello tenemos que establecer su concepto y alcances, lo que de suyo es bastante complejo, derivado de que los derechos en estudio han sido confundidos e incluso utilizados como sinónimos tanto por la doctrina (Celis Quintal, 2000, p. 103) como por la propia corte mexicana (Escalera, 2008, p. 229), empero existen diferencias que los edifican como dos derechos perfectamente diferenciados, entre quienes distinguen con claridad ambos derechos encontramos a la derogada Ley Orgánica 5/1992 de octubre de España, en su exposición de motivos determinaba que (España, 1992):

... Nótese que se habla de la privacidad y no de la intimidad: Aquélla es más amplia que ésta, pues en tanto la intimidad protege la esfera en que se desarrollan las facetas más singularmente reservadas de la vida de la persona - el domicilio donde realiza su vida cotidiana, las comunicaciones en las que expresa sus sentimientos, por ejemplo-, la privacidad constituye un conjunto, más amplio, más global, de facetas de su personalidad que, aisladamente consideradas, pueden carecer de significación intrínseca pero que, coherentemente enlazadas entre sí, arrojan como precipitado un retrato de la personalidad del individuo que éste tiene derecho a mantener reservado.

La doctrina jurídica coincide en estimar que son derechos diferenciados y que el ámbito de la intimidad es más restringido, Martí de Gidi (2009), afirma que la privacidad es distinta de la intimidad, toda vez que la vida privada alude a aquellos aspectos de la vida de una persona que ofrecen algún nexo o relación con lo social ya sea por cuestiones de índole laboral, profesional o comercial, aspectos que exceden a su juicio el ámbito de la intimidad. 
Rovira por su parte, afirma que los aspectos que tutela la privacidad exceden en mucho a los de la intimidad, ya que la primera salvaguarda aspectos de la vida de una persona relacionados con su rol social incluso en su ámbito laboral o comercial, que evidentemente no están imbíbitos en el derecho a la intimidad, porque este derecho se concibe involucrando aspectos tan personales como sentimientos, pensamientos, sexualidad y todo aquello que forma parte de los más interior y reservado del individuo (Cobos Campos, 2013, pp. 45-81)

Es importante asentar que algunos doctrinarios (Celis Quintal, 2009, p. 74), con cuya opinión no concordamos, y la propia Suprema Corte en México utilizan como sinónimos o derechos equivalentes los de intimidad y privacidad. Entre ellos destacamos a Meins Olivares (2000), para quién la intimidad es "la facultad de cada persona para determinar por sí misma, cómo, cuándo y qué cantidad de información suya puede ser comunicada a los demás, previa evaluación si dicha comunicación pueda o no acarrearle un daño moral o patrimonial" (p. 222), y añade que no existe "distinción jurídica" en el uso de la palabra privacidad y la intimidad, ya que el ordenamiento chileno alude a vida privada, que no excluye, a su juicio, al concepto de intimidad (Meins Olivares, 2000, p. 222).

En cuanto a la Suprema Corte en México, la misma claramente ha utilizado como sinónimos a ambos derechos en la determinación misma de la existencia implícita del derecho, ya que resulta evidente que al no existir el derecho a la intimidad consagrado expresamente en la Constitución, se ha ido desarrollando a través de la interpretación de la existencia de ese derecho implícito a que nuestro máximo tribunal que sin embargo dista mucho de tener el desenvolvimiento y la técnica jurídica de otros países que sí tienen el derecho expresamente consagrado en sus cartas fundamentales.

Por su interés insertaremos la tesis en la que nuestro Máximo Tribunal determina que el derecho a la intimidad está comprendido en el artículo 16 de nuestra Constitución, tesis que bajo el rubro DERECHO A LA PRIVACIDAD O INTIMIDAD. ESTÁ PROTEGIDO POR EL ARTÍCULO 16, PRIMER PÁRRAFO, DE LA CONSTITUCIÓN POLÍTICA DE LOS ESTADOS UNIDOS MEXICANOS es del siguiente tenor:

Dicho numeral establece, en general, la garantía de seguridad jurídica de todo gobernado a no ser molestado en su persona, familia, papeles o posesiones, sino cuando medie mandato de autoridad competente debidamente fundado y motivado, de lo que deriva la inviolabilidad del domicilio, cuya finalidad primordial es el respeto a un ámbito de la vida privada personal y familiar que debe quedar excluido del conocimiento ajeno y de las intromisiones de los demás, con la limitante que la Constitución Política de los Estados Unidos Mexicanos establece para las autoridades. En un sentido amplio, la referida garantía puede extenderse a una protección que va más allá del aseguramiento del domicilio como espacio físico en que se desenvuelve normalmente la privacidad o la intimidad, de lo cual deriva el reconocimiento en el artículo 16, primer párrafo, constitucional, de un derecho a la intimidad o vida privada de los gobernados que abarca las intromisiones o molestias que por cualquier medio puedan realizarse en ese ámbito reservado de la vida. (Escalera, 2008, p. 229).

Otros conceptos de intimidad los encontramos en Albaladejo, y Zavala de González, el primero de ellos afirma que "es el poder concedido a la persona sobre el conjunto de actividades que 
forman su círculo íntimo, poder que le permite excluir a los extraños de entrometerse en él" (Albaladejo, 1969, pp. 494-495) y la segunda, Zavala de González afirma que es " el derecho personalísimo que protege la reserva espiritual de la vida privada del hombre, asegurando el libre desenvolvimiento de éste en lo personal, en sus expresiones y en sus afectos" (Zavala de González, 1982, p. 87).

En consecuencia, vistos los parámetros analizados podemos conceptuar a la privacidad parafraseando a Altman (1999), como "el control selectivo del acceso a uno mismo o al grupo al que uno pertenece" (pp. 22-24), y a la intimidad como "Derecho humano fundamental, autónomo, que tutela los aspectos auto-reservados de la vida de las personas de injerencias arbitrarias e ilícitas de terceros y del estado" (Cobos Campos, 2011).

La intimidad como derecho parte de la posibilidad de sustraerse a lo público, el derecho sajón alude al término "to be let alone", que traduciríamos literalmente como el derecho a que te dejen en paz, sin embargo el ámbito de protección del mismo en la actualidad va más allá de lo mencionado, ya que en sus orígenes, se ha dicho que se "identificaba como el secreto y el reconocimiento a su titular de facultades de exclusión" (Gómez Martínez, 2004, p. 110), en cambio en la actualidad, ha tenido una forzosa evolución derivada del perfeccionamiento de las nuevas tecnologías de control y vigilancia, que lo han convertido para algunos doctrinarios y órganos jurisdiccionales en un medio de control de las informaciones que respecto a su persona puedan poseer otros, esto es " capacidad de determinar cómo, cuándo y en qué medida se comunica información a otros" (Gómez Martínez, 2004, p. 111).

Así concebidos y diferenciados ambos derechos, con las pertinentes observaciones en cuanto a su uso como derechos equivalentes, debemos entrar en el apartado subsecuente a analizar el entorno jurídico que se ha construido alrededor de los correos electrónicos y la supervisión patronal de estos.

\section{Los correos electrónicos empresariales y los derechos de supervisión del patrón}

En principio, siguiendo la Directiva 2002/58 CE del Parlamento Europeo y del Consejo de 12 de julio de 2002, relativa al tratamiento de datos personales y a la protección de la intimidad en el sector de las comunicaciones electrónicas, entendemos como correo electrónico "todo mensaje de texto, voz, sonido o imagen enviado a través de una red de comunicaciones pública que pueda almacenarse en el equipo terminal del receptor hasta que éste acceda al mismo" (Rebollo Delgado, \& Serrano Pérez, 2008, p. 117).

En términos generales la doctrina (Ovalle Favela, 2013, pp. 1801-1814) y la ley estiman que la protección de esta forma de comunicación resulta esencial para la salvaguarda de los derechos a la intimidad y privacidad a que se contrae el presente estudio; sin embargo la corte mexicana no coincide con tal criterio ya que ha determinado que el derecho a las comunicaciones privadas es un derecho distinto e independiente del derecho a la intimidad, así se desprende de la siguiente tesis: 
DERECHO A LA INVIOLABILIDAD DE LAS COMUNICACIONES PRIVADAS. SUS DIFERENCIAS CON EL DERECHO A LA INTIMIDAD. A pesar de ser una manifestación más de aquellos derechos que preservan al individuo de un ámbito de actuación libre de injerencias de terceros -como sucede con el derecho a la intimidad, a la inviolabilidad del domicilio o la protección de datos personales -, el derecho a la inviolabilidad de las comunicaciones privadas posee una autonomía propia reconocida por la Constitución. En cuanto a su objeto, el derecho a la inviolabilidad de las comunicaciones se configura como una garantía formal, esto es, las comunicaciones resultan protegidas con independencia de su contenido. En este sentido, no se necesita en modo alguno analizar el contenido de la comunicación, o de sus circunstancias, para determinar su protección por el derecho fundamental. Este elemento distingue claramente al derecho a la inviolabilidad de las comunicaciones de otros derechos fundamentales, como es el de la intimidad. En este último caso, para considerar que se ha consumado su violación, resulta absolutamente necesario acudir al contenido de aquello de lo que se predica su pertenencia al ámbito íntimo o privado. En definitiva, lo que se encuentra prohibido por el artículo 16 de la Constitución Política de los Estados Unidos Mexicanos, en su párrafo decimosegundo, es la intercepción o el conocimiento antijurídico de una comunicación ajena. La violación de este derecho se consuma en el momento en que se escucha, se graba, se almacena, se lee o se registra- sin el consentimiento de los interlocutores o sin autorización judicial- una comunicación ajena, con independencia de que, con posterioridad, se difunda el contenido de la conversación interceptada. (Suprema Corte de Justicia de la Nación, 2011).

En tal orden de ideas, deberemos entender que el derecho a la inviolabilidad de las comunicaciones se tutela independiente a los derechos en análisis y por tanto su conculcación no atiende a la de estos. Igualmente ha analizado nuestro máximo tribunal los aspectos que están relacionados con el correo electrónico y su carácter privado, lo anterior se desprende de la siguiente tesis:

DERECHO A LA INVIOLABILIDAD DE LAS COMUNICACIONES PRIVADAS. MOMENTO EN EL CUAL SE CONSIDERA INTERCEPTADO UN CORREO ELECTRÓNICO. El correo electrónico se ha asemejado al correo postal, para efectos de su regulación y protección en el ordenamiento jurídico. Sin embargo, es necesario identificar sus peculiaridades a fin de estar en condiciones de determinar cuándo se produce una violación a una comunicación privada entablada por este medio. ... el correo electrónico se configura como un sistema de comunicación electrónica virtual, en la que el mensaje en cuestión se envía a un "servidor", que se encarga de "enrutar" o guardar los códigos respectivos, para que el usuario los lea cuando utilice su operador de cuenta o correo. La utilización del correo electrónico se encuentra supeditada a una serie de pasos determinados por cada servidor comercial. Así, es necesario acceder a la página general del servidor en cuestión, donde se radican todos los mensajes de la cuenta de correo contratada por el titular. Esta página suele estar compuesta por dos elementos: el nombre de usuario (dirección de correo electrónico del usuario o login) y la contraseña (password). De vital importancia resulta la contraseña, ya que ésta es la llave personal con la que cuenta el usuario para impedir que terceros puedan identificarla y acceder a la cuenta personal del usuario. La existencia de esa clave personal de seguridad que tiene todo correo electrónico, lo reviste de un contenido privado y por lo tanto investido de todas las garantías derivadas de la protección de las comunicaciones privadas y la intimidad. En esta lógica, se entenderá que un correo electrónico ha sido interceptado cuando- sin autorización judicial o del titular de la cuenta- se ha violado el password o clave de seguridad. Es en ese momento, y sin necesidad de analizar el contenido de los correos electrónicos, cuando se consuma la violación al derecho fundamental a la inviolabilidad de las comunicaciones privadas. No sobra señalar, que si bien es cierto que un individuo puede autorizar a otras personas 
para acceder a su cuenta-a través del otorgamiento de la respectiva clave de seguridad-, dicha autorización es revocable en cualquier momento y no requiere formalidad alguna. Asimismo, salvo prueba en contrario, toda comunicación siempre es privada, salvo que uno de los intervinientes advierta lo contrario, o bien, cuando de las circunstancias que rodean a la comunicación no quepa duda sobre el carácter público de aquélla. (Suprema Corte de Justicia de la Nación, 2011).

Como es fácil advertir al aludir a los correos electrónicos nuestro máximo tribunal retoma al derecho a la intimidad que le asigna al usuario del correo y supedita su acceso a la autorización del titular de la cuenta, por lo que cabe preguntarse si en el correo de la fuente de trabajo podemos realmente hablar de que el trabajador es el titular o lo es el patrón, ello dentro de la misma resolución de amparo que da vida a sendas tesis aisladas, y debemos añadir una tercera tesis emanada del mismo amparo, con el mismo carácter de aislada en la que la corte determina que no importa quién es el propietario de la computadora puesto que ello no legitima a su propietario para acceder al correo, puesto que siendo una de las características del correo su virtualidad y ubicuidad, lo que se preserva es la comunicación en sí, con independencia del tipo de computador y su propietario que son cuestiones para nuestro máximo tribunal "accidentales" (Suprema Corte de Justicia de la Nación, 2011).

Empero, el multicitado amparo resuelve en relación a cuestiones materia del derecho familiar, en consecuencia, por lo que al correo electrónico del trabajador atañe, en nuestro país no encontramos una construcción tan estructurada del tema como lo ha hecho verbigracia el derecho Español, éste, en principio, se inclinó por establecer el derecho del patrón a supervisar los correos del trabajador, este criterio se vio claramente reflejado en la Ley del estatuto de los Trabajadores, que en su artículo 20.3, en lo conducente, determinó que:

... el empresario podrá adoptar las medidas que estime más oportunas de vigilancia y control para verificar el cumplimiento por el trabajador de sus obligaciones y deberes laborales, guardando en su adopción y aplicación la consideración debida a su dignidad humana y teniendo en cuenta la capacidad real de los trabajadores disminuidos, en su caso. (España, 1995).

Cabe igualmente mencionar, por su estrecha relación con el tema en análisis el numeral 18 del mismo estatuto que determina en lo conducente:

Sólo podrán realizarse registros sobre la persona del trabajador, en sus taquillas y efectos particulares, cuando sean necesarios para la protección del patrimonio empresarial y del de los demás trabajadores de la empresa, dentro del centro de trabajo y en horas de trabajo. En su realización se respetará al máximo la dignidad e intimidad del trabajador y se contará con la asistencia de un representante legal de los trabajadores o, en su ausencia del centro de trabajo, de otro trabajador de la empresa, siempre que ello fuera posible. (Ley del Estatuto de los Trabajadores, 1995).

Aludimos a éste último precepto, ya que en el 2007 es hecho valer, en una resolución emblemática del Tribunal Supremo Español en la Sala de lo Social, el caso desencadena una serie de análisis que la sala estima necesarios para establecer baremos respecto al alcance y la forma del control 
empresarial sobre el uso por el trabajador del ordenador que se ha facilitado por la empresa como instrumento de trabajo.

Así las cosas la sala estima que no se violentan los derechos humanos del trabajador al acceder a la computadora, en principio porque se trata de un instrumento de trabajo y porque ". . . en él se cumple la prestación laboral y, por tanto, ha de comprobarse si su uso se ajusta a las finalidades que lo justifican, ya que en otro caso estaría retribuyendo como tiempo de trabajo el dedicado a actividades extra-laborales. .." (Sentencia de la sala, 2007). Añadiendo la sala, que el patrón tiene el derecho de controlar los resultados para garantizar la continuidad en el desempeño laboral, e igualmente cuidar la protección del sistema informático de la empresa que puede ser dañado por usos indebidos (Sentencia de la sala, 2007).

Este criterio ha seguido prevaleciendo en España, e incluso ha ido más allá en una resolución del 2011, donde determina que "si la empresa prohíbe totalmente el uso de estas tecnologías con fines particulares, ya sea dentro o fuera del horario laboral, no se puede entender que el Derecho Fundamental a la Intimidad o al Secreto de las comunicaciones opera en el uso de estos equipos" (Sentencia de la sala, 2011).

Para definir si esto es posible, con mayor claridad la posición de los tribunales españoles la Sala de lo Penal del tribunal Supremo en un asunto en el que se aportó como prueba el correo electrónico de un trabajador determinó:

... el ordenador registrado era una herramienta propiedad de la empresa y facilitada por la empresa a don ... exclusivamente para desarrollar su trabajo, por lo que entendemos que incluso en aquel supuesto en que pudiera utilizar el ordenador para emitir algún tipo de mensaje de carácter personal, entendemos que al utilizar precisamente un ordenador ajeno, de la empresa, y destinado exclusivamente para el trabajo a la empresa, estaba asumiendo -cediendo- la falta de confidencialidad -secreto- de las comunicaciones que pudiera tener el señor . . . utilizando tal terminal informático... (Sentencia de la sala, 2014).

En otro orden de ideas, el Grupo de trabajo de la Unión Europea (Grupo de Trabajo sobre Protección de Datos, 2002, p. 4) relativo a la vigilancia de las comunicaciones electrónicas en el lugar de trabajo, determinó que:

... los trabajadores no dejan su derecho a la vida privada y a la protección de datos cada mañana a la puerta de su lugar de trabajo. Esperan legítimamente encontrar allí un grado de privacidad, ya que en él desarrollan una parte importante de sus relaciones con los demás. Este derecho, no obstante, debe conciliarse con otros derechos e intereses legítimos del empleador, en particular, su derecho a administrar con cierta eficacia la empresa y sobre todo, su derecho a protegerse de la responsabilidad o el perjuicio que pudiera derivarse de las acciones de los trabajadores...

Sin embargo, el referido grupo hace hincapié en que el empleador debe decantarse prima facie por la prevención en lugar de utilizar la detección, e incluso recomiendan que se permita al trabajador manejar dos cuentas una de uso profesional exclusivo y otra privada (Grupo de Trabajo sobre Protección de Datos, 2002, p. 5). 
El Tribunal Europeo de Derechos Humanos, por su parte ha establecido precedentes en los que determina que la protección de la vida privada no se limita al hogar sino que se extiende al lugar de trabajo (Sarmiento, Mieres, \& Linera, (n.d.)).

No encontramos alusión expresa al problema en nuestra jurisprudencia, y por lo que hace a la Ley Federal del Trabajo, la misma alude en el capítulo de pruebas, artículo 776, frac. VIII al correo electrónico como medio de prueba, siendo esta la única alusión que encontramos al respecto.

Useche Castro (2012, pp. 47-59), analizando los alcances del problema a la luz de la constitución venezolana, concluye que el patrón para revestir de legitimidad los procedimientos de supervisión deberá hacer del conocimiento de este cuáles serán los mecanismos para la realización de tales actos de control y el trabajador deberá ser conforme con ellos, ya que de lo contrario el patrón será responsable de la vulneración de los derechos fundamentales a la intimidad y privacidad del trabajador.

\section{Conclusiones}

No existen en nuestro país mecanismos legislativos claros ni idóneos para establecer los límites entre los derechos de supervisión del patrón y los derechos fundamentales del trabajador frente al primero.

Sin embargo, contrario a lo sostenido por los tribunales españoles, estimamos que los derechos en pugna no son del mismo nivel, toda vez que los derechos a la intimidad y a la privacidad son derechos fundamentales y los derechos de supervisión patronal no lo son, por lo que en última instancia, serían los del primero mencionado, los que deberían tutelarse prima facie.

Si damos continuidad a las tesis aisladas analizadas, deberemos concluir que para nuestro máximo tribunal no tiene importancia que las computadoras que usa el trabajador sean propiedad de la empresa o dicho de otra forma, no trasciende quién detenta la propiedad del equipo, por lo que este argumento utilizado por el Tribunal Supremo Español a que hemos hecho alusión en párrafos antecedentes, no tendría cabida en nuestro derecho, ya que la corte ha dejado en claro que lo que se tutela es el proceso de comunicación en sí, sin que trascienda la propiedad del equipo electrónico utilizado a tal fin.

Lo que si resulta trascedente para nuestro análisis a la luz de la construcción nacional que ha hecho la corte en torno a la protección de las comunicaciones privadas, es la titularidad de la cuenta de correo, en vista de ello estimamos que si el titular o propietario de la cuenta de correo es el empleador para nuestro máximo tribunal no existiría óbice para que el patrón ingresase a ella, pero si es personal del trabajador estaría definitivamente impedido para ello.

La solución del problema deberá en última instancia ser legislativa ya que nuestros ordenamientos no han elaborado, como lo han hecho otros ordenamientos, una adecuada regulación de las facultades de supervisión del patrón. 


\section{Propuesta}

Se propone, como mecanismo mínimo de control, la adición al artículo 25 de Ley Federal del Trabajo de un inciso en el que se establezca el requerimiento de insertar en las condiciones de trabajo los mecanismos de supervisión patronal que se utilizarán en la relación laboral, por lo que el artículo quedaría del siguiente tenor:

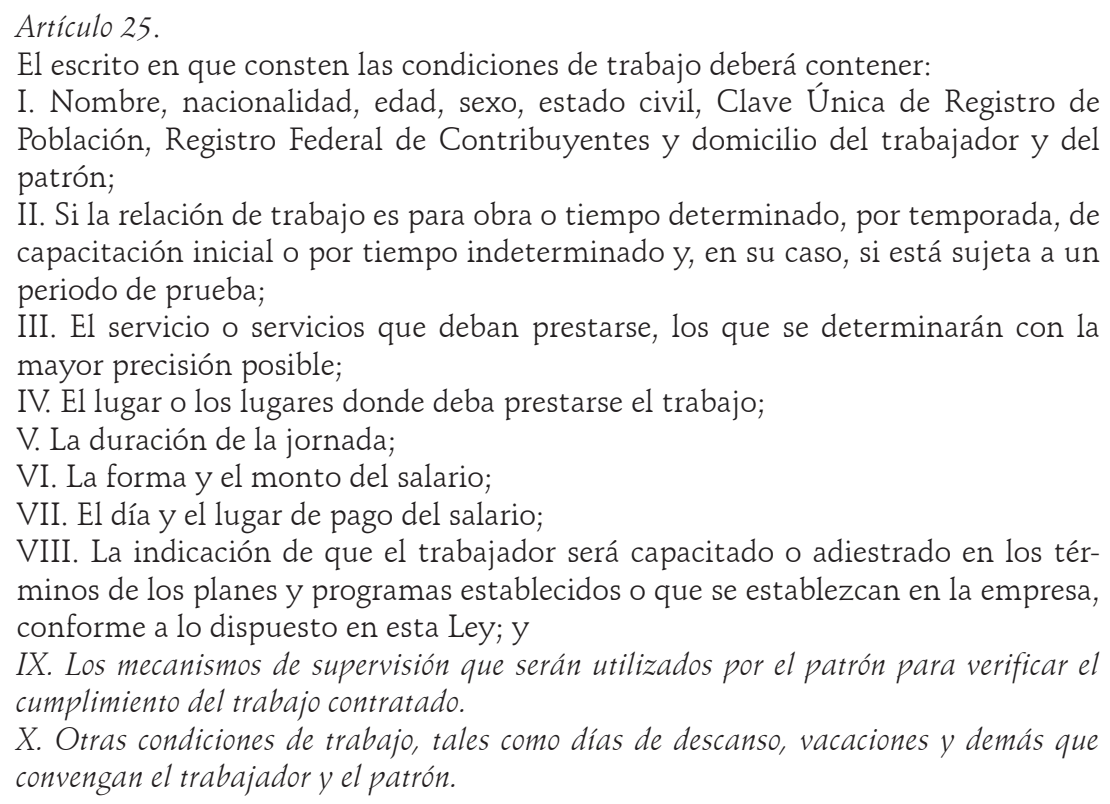

\section{Referencias}

Albaladejo, M. (1969). Derecho Civil. Barcelona: Bosch.

Altman, I. (1975). The environment and social behavior: Privacy, personal space, territoriality, and crowding. California: Brooks/Cole.

Bru Cuadrada, E. (2007). La protección de datos en España y en la Unión Europea. Especial referencia a los mecanismos jurídicos de reacción frente a la vulneración del derecho a la intimidad. Revista de los Estudios de Derecho y Ciencia Política de la UOC, (5): 78-92. Retirado de http://www. uoc.edu/idp/5/dt/esp/bru.pdf

Calle Sol, B. (2009). El contenido del derecho a la intimidad. Revista Precedente, Cali.

Celis Quintal, M. A. (2006). La protección de la intimidad como derecho fundamental de los mexicanos. In D. Cienfuegos Salgado, \& M. C. Macías Vázquez (Coords.), Estudios en homenaje a Marcia Muñoz de Alba Medrano: Protección de la persona y derechos fundamentales (pp. 71-108). México: UNAM.

Cobos Campos, A. P. (2013, julio-diciembre). El contenido del derecho a la intimidad. Cuestiones Constitucionales, (29), 45-81. 
Cobos Campos, A. P. (2011). El derecho a la intimidad y la exigencia de su constitucionalización, (Doctoral thesis, Facultad de Derecho de la Universidad Autónoma de Chihuahua, Chihuahua.

Escalera, M. A. P. (2008, mayo). Derecho a la privacidad o intimidad. Está protegido por el artículo 16, primer párrafo, de la constitución política de los Estados Unidos Mexicanos. Semanario Judicial de la Federación y su Gaceta, 27, 229. Recuperado de https://sjf.scjn.gob.mx/sjfsist/Documentos/ Tesis/169/169700.pdf

España. Ley Orgánica 5/1992 de Regulación del Tratamiento Automatizado de los Datos de Carácter Personal. Madrid, n. 262, 29 octubre 1992.

España. Real Decreto Legislativo 1/1995, de 24 de marzo, por el que se aprueba el texto refundido de la Ley del Estatuto de los Trabajadores. Madrid, n. 75, marzo 1995.

Ferrajoli, L. (2001). Los fundamentos de los derechos fundamentales. Madrid: Ed. Trotta.

Gómez Martínez, C. (2004). El ejercicio de acciones civiles de protección de la intimidad del usuario de internet. Aspectos procesales. Derecho a la intimidad y nuevas tecnologías. Cuadernos de Derecho Judicial, Madrid: Consejo General del Poder Judicial.

Grupo de Trabajo sobre Protección de Datos - Artículo 29 (2002 mayo 29). Documento de trabajo relativo a la vigilancia de las comunicaciones electrónicas en el lugar de trabajo. Recuperado de http:// ec.europa.eu/justice/policies/privacy/docs/wpdocs/2002/wp55_es.pdf

Holmes, M., \& Shand, D. (1995). Management Reform: Some Practitioner Perspective on the past ten years. Governance, 551-558.

Ley del Estatuto de los Trabajadores, 23 de octubre de 1995.

Martí de Gidi, L. del C. (2003 marzo-septiembre) Vida privada, honor, intimidad y propia imagen como derechos humanos. Letras Jurídicas, (8), 233-253.

Meins Olivares, E. (2000). Derecho a la intimidad y a la honra en Chile. Ius et Praxis, 6(1), 303-319.

México (1917). Constitución Política de los Estados Unidos Mexicanos. Congreso Constituyente.

México. Ley Federal del Trabajo, abril 1970.

Nikken, P. (n.d.). El concepto de derechos humanos. Retirado de http://www.derechoshumanos. unlp.edu.ar/assets/files/documentos/el-concepto-de-derechos-humanos.pdf

Ovalle Favela, J. (2013). Artículo 16. Intervención de las comunicaciones privadas y jueces de control. In E. Ferrer Mac-Gregor, J. L. Caballero Ochoa, \& C. Steiner (Coord.), Derechos Humanos en la Constitución: Comentarios de jurisprudencia constitucional e interamericana (pp. 1801-1814). México: IIJ/SCJN/Fundación Konrad Adenauer.

Pacheco Escobedo, A. (2011). Los derechos de la personalidad. México: UNAM/Porrúa.

Pérez Luño, A. E. (2016). Nuevo derecho, nuevos derechos. Anuario de filosofía del derecho, (32): 1536. 
Peso Navarro, E., Peso Ruiz, M., Ruiz Gomes, A., \& Peso Ruiz, N. (2011). Vocabulario español actualizado de Iustecnología de la información. Madrid: Ediciones Díaz de Santos.

Rebollo Delgado, L., \& Serrano Pérez, M. M. (2008). Introducción a la protección de datos. 2nd ed. Madrid: Dykinson.

Sarmiento, D., Mieres, L. J. M., \& Linera, M. A. P. (n.d.). Las sentencias básicas del Tribunal Europeo de Derechos Humanos. Retrieved from: http://personal.us.es/juanbonilla/contenido/CM/TRIBUNAL\%20EUROPEO\%20DE\%20DERECHOS\%20HUMANOS/JURISPRUDENCIA\%20TEDH/ SENTENCIAS\%20BASICAS\%20DEL\%20TEDH.pdf

Sentencia de la sala de lo Penal del Tribunal Supremo (2844/2014), 16 junio 2014.

Sentencia de la Sala de lo Social del Tribunal Supremo (RJ 2007\7514), 26 septiembre 2007.

Sentencia de la Sala de lo Social del Tribunal Supremo, 6 octubre 2011.

Solar Rojas, J. del (2000). Los Derechos Humanos y su Protección. Lima: Fondo Editorial de la Universidad Inca Garcilaso de la Vega.

Suárez Crothers, C. (2000, diciembre). El concepto de derecho a la vida privada en el derecho anglosajón y europeo. Revista de Derecho, 11.

Suprema Corte de Justicia de la Nación, Amparo directo en revisión 1621/2010, 15 junio 2011, Tesis aislada CLIX/2011.

Suprema Corte de Justicia de la Nación, Amparo directo en revisión 1621/2010, 15 junio 2011, Tesis aislada CLX/2011.

Suprema Corte de Justicia de la Nación, Amparo directo en revisión 1621/2010, 15 junio 2011, Tesis aislada CLIII/2011.

Tribunal Europeo de Derechos Humanos. Caso Niemitz c. Alemania, 16 diciembre 1992. https:// pt.scribd.com/doc/279257760/TEDH-Caso-Niemietz-c-Alemania

Useche Castro, Y. C. (2012). El dilema entre el derecho a la intimidad y el secreto a las comunicaciones del trabajador y poder de vigilancia y control del patrono. Revista Derecho y Tecnología, (13), 47-59.

Valera, S. (1999). Espacio privado, espacio público: Dialécticas urbanas y construcción de significados, Tres al Cuarto, (6), 22-24.

Zavala de González, M. (1982). Derecho a la Intimidad. Buenos Aires: Abeledo-Perrot.

Data da submissão: 07 de junho de 2016

Aceito em: 12 de abril de 2017 
